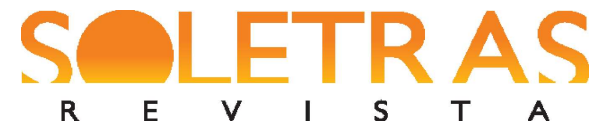

N. 40 - 2020.2 - PATRICIA APARECIDA GONÇALVES DE FARIA

\title{
A escrita de Graciliano Ramos nas páginas de Cultura Política: revista mensal de estudos brasileiros
}

Patrícia Aparecida Gonçalves de Faria ${ }^{1}$

\begin{abstract}
Resumo: Aliando a prática da escrita de romances e contos com a imprensa, Graciliano Ramos (1892-1953), colaborou durante os anos de 1941 a 1944, com Cultura Política: revista mensal de estudos brasileiros (1941-1944), principal publicação do Departamento de Imprensa e Propaganda (DIP), controlado pelo Estado Novo, responsável pela sua prisão em 1936, sem a mínima acusação formal. Assim, considerando o percurso intelectual e literário do autor de Vidas Secas, este artigo pretende, a partir de teóricos como Antelo (1984), Andrade (1941), Candido (2001), Salla(2010), Velloso (1982), entre outros, levantar as características da revista e as suas estratégias para manter em seu rol de colaboradores figuras importantes, como Graciliano Ramos e, ainda, levantar as publicações do autor para o periódico verificando as estratégias de escrita utilizadas pelo escritor para servir o Estado sem, contudo, se render a ideologia do governo.
\end{abstract}

Palavras-chave: Graciliano Ramos. Cultura Politica. crônicas.

\section{Cultura Política: revista mensal de estudos brasileiros}

Tentando evitar confrontos diretos com os intelectuais que não almejavam apoiar o regime do Estado Novo, o governo procurou contornar os posicionamentos desses escritores no anseio de impedir que fosse feita uma oposição aberta a Getúlio Vargas, mesmo vigorando a censura, fortemente exercida pelo DIP. Para tal intento, criou a revista Cultura Política: revista mensal de estudos brasileiros, com o intuito de promover um discurso voltado para a constituição de uma ação política preocupada com a construção de uma nova ordem, engajada em enfatizar e propagar o "novo" conceito de governar, segundo os moldes estadonovista.

Cultura Política: revista mensal de estudos brasileiros, que circulou de março de 1941 a outubro de 1945, foi o periódico de maior força e durabilidade ao longo da ditadura Vargas, vendida nas principais bancas de jornal do país por um valor simbólico de $\mathrm{Cr} \$ 3,00$, sendo que uma assinatura anual correspondia a $\mathrm{Cr} \$ 30,00$. Todavia, o seu custo unitário ultrapassava a quantia de $\mathrm{Cr} \$ 10,00$. Nesse sentido, fica atestado que a finalidade do periódico era divulgar o governo e os seus feitos culturais no país sem a mínima intenção de lucrar com as suas

\footnotetext{
${ }^{1}$ Doutora em Letras, na área de Teoria e Estudos Literários pela UNESP. Atua principalmente nos seguintes temas: literatura brasileira, literatura italiana, literatura comparada, século XX. Brasil. E-mail: patricia_faria09@yahoo.com.br Orcid: https://orcid.org/0000-0003-4039-3884
} 


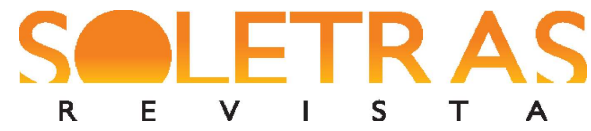

N. 40 - 2020.2 - PATRICIA APARECIDA GONÇALVES DE FARIA

publicações. Logo, apenas uma parcela mínima desses exemplares era distribuída pelo DIP.

No decorrer de sua existência foram publicados cinquenta números com uma tiragem mensal de aproximadamente 3.000 exemplares que contavam com aproximadamente 300 páginas medindo 16 x 22,5 cm. A exceção ficou por conta dos três últimos números que, com o fim da Agência Nacional, reduziram as suas páginas para cento e poucas numa medida de 13,50 x 18,50 cm; todas as publicações da revista foram realizadas por Fernando Chinaglia S/A.

Inicialmente, Cultura Política utilizava uma linguagem formal e literária. Contudo, com o tempo e diante das suas transformações, permitiu-se o uso de uma linguagem mais coloquial, mais próxima dos temas inerentes à realidade cotidiana do período, como por exemplo, a entrada no Brasil na segunda guerra mundial.

Desde a sua fundação em março de 1941 até a sua extinção em outubro de 1945, a revista foi dirigida por Almir Bonfim de Andrade a convite de Lourival Fontes, diretor do DIP. Almir de Andrade ficou à frente da revista durante as cinquenta edições que foram controladas pelo DIP e, mesmo com o fim do departamento, por sua própria iniciativa, ainda mais três números foram estampados em agosto, setembro e outubro de 1945, como informa Raul Antelo: “[...] Amparada pelo aparelho estatal, Cultura Política conseguiu publicar cinquenta números, aparecendo o último em maio de 1945. Dissolvida a Agência Nacional, Almir de Andrade consegue imprimir ainda mais três, em agosto, setembro e outubro desse ano" (ANTELO, 1984. p.11.)

Vale salientar que no sumário, na maioria das publicações, antes da enumeração das seções havia um artigo escrito pelo diretor da revista que assinava no final dos escritos como A. de A. Em seguida, no mesmo sumário, apareciam as seis seções fixas enumeradas que perdurariam até agosto de 1942, na edição de número 18. Entretanto, alguns conflitos no DIP e o início da participação do Brasil na segunda guerra mundial obrigaram a revista a adequar as suas publicações aos novos rumos nacionais a fim de alertar a população sobre a guerra. Com isso, muitas das várias temáticas abordadas pela revista foram mantidas, outras seções, por sua vez, foram agrupadas e outras, ainda, foram extintas, dando lugar à novas seções.

Quanto ao título de Cultura Política, o próprio Almir de Andrade em "Política e Cultura", texto introdutório da revista, comenta as relações existentes entre cultura e política, temas que seriam incessantemente discutidos ao longo da existência do periódico: 


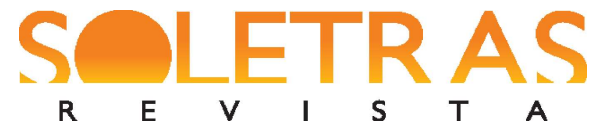

N. 40 - 2020.2 - PATRICIA APARECIDA GONÇALVES DE FARIA

Cultura e política são [...] indissociáveis: toda política verdadeira e sadia deve ser uma expressão de cultura popular, assim como toda cultura verdadeira e fecunda deve ter um sentido político; deve conter uma aspiração de integrarse na vida organizada que a política representa, com cristalização da ordem social. (ANDRADE, 1941, p.7)

Em relação ao subtítulo: revista mensal de estudos brasileiros, podemos inferir que o objetivo era explicar as transformações sociais e políticas do país como um todo, almejando integrar todas as regiões no novo contexto político com bases fixadas no plano nacional. Para tal intento, as publicações mensais realizavam estudos nos mais variados setores da política e da cultura: economia, técnica, arte, literatura, ciências, música, rádio, educação, cinema, teatro etc.

\begin{abstract}
A Cultura Política, conforme enuncia o seu subtítulo, configura-se uma revista de "estudos brasileiros", cuja proposta é a de "definir" e "esclarecer" o rumo das transformações sociais e políticas do país. As realizações do governo nos mais diversos setores - política, economia, técnica, artes, letras, ciências - são registradas. A revista anuncia os seus propósitos de promover e estimular o debate sobre a problemática regional, desde que se circunscreva ao contexto nacional. (VELLOSO, 1982, p. 74-75)
\end{abstract}

Assim, pode-se dizer que a principal finalidade da revista era estudar, determinar e esclarecer as transformações sócio-econômicas que aconteciam no país. Ela, ainda, relatava as realizações e os feitos governamentais, e funcionava como um veículo de divulgação das publicações e feitos realizados por Getúlio Vargas e o Estado Novo: "Cultura Política, uma das publicações promovidas pelo Estado Novo, ligada diretamente ao Departamento de Imprensa e Propaganda (DIP), apresentava como primeiro objetivo a divulgação das mudanças do país e as iniciativas governamentais" (PETERLE, 2010, p. 74).

Com o objetivo de divulgar as mudanças que aconteciam no país por meio das iniciativas governamentais, a revista precisou de um grande investimento financeiro. Por dispor de recursos vultosos, pagou a seus colaboradores o dobro do que era oferecido pelo mercado jornalístico da época. Assim sendo, o intuito do governo não era lucrar com as publicações e sim propagar os diversos estudos mensais realizados pela revista com o próposito de unificar a cultura e a política.

Desta forma, devido as suas qualidades editoriais, a sua extensão e ao grande 
investimento financeiro, conseguiu fazer jus à sua missão, ou seja, com coerência estampou em suas páginas particularidades culturais de várias áreas, de modo que conseguiu reunir uma grande quantidade de colaboradores de grande capacidade e reconhecimento intelectual.

Como já mencionado, para fundamentar o seu propósito de atuar em diversas áreas da cultura e da política, a revista precisou recrutar inúmeros colaboradores. A última seção, intitulada "Brasil social, intelectual e artístico", contou com figuras renomadas que escreviam sobre temas relacionados à arte e à cultura nas subseções. Exemplos notáveis são: Marques Rebelo em "Quadros e Costumes do Centro e do Sul”, Graciliano Ramos em "Quadros e Costumes do Nordeste", Lúcio Cardoso em "Cinema", Wilson Louzada em "Literatura de Ficção", Guerreiro Ramos em "Literatura Latino-americana”, entre outros.

Detenhamo-nos [...] em algumas figuras que colaboraram na seção literária de publicação. Com rígida hierarquização, a revista cedia um espaço para cada um. Assim, o sexto capítulo da publicação - "Brasil social, intelectual e artístico" - abria-se invariavelmente com uma justificativa da influência política sobre a evolução social, intelectual e artística do Brasil. A seguir, em "A evolução social", ainda se discorria sobre a ordem política e a evolução social, para só então incluir as seções propriamente ditas: os "Quadros e costumes do Centro-Sul", a cargo de Marques Rebelo, e os do Nordeste, escritos por Graciliano Ramos; a página de Basílio de Magalhães, "O povo brasileiro através do folclore", e outras de recuperação e homenagem: "Intérpretes da vida social brasileira" a "Páginas do passado brasileiro". $\mathrm{Na}$ segunda parte - "Evolução intelectual" -, apareciam rubricas de Wilson Louzada ("Literatura de ficção"), Prudente de Morais Neto ("Literatura de idéias"), Hélio Viana ("Literatura e história"), Guerreiro Ramos ("Literatura latino-americana"), Rosário Fusco ("História literária do Brasil”), F. Venâncio Filho ("Educação"), Antônio Simões dos Reis( "Movimento bibliográfico") e Carlos Pedrosa ( "Bibliografia etrangeira sobre o Brasil"). No último item de "Evolução artística", apareciam textos de Luís Heitor (música); Carlos Cavalcânti (artes plásticas); R. Magalhães Jr. (teatro); Lúcio Cardoso (cinema) e Martins Castelo (Marques Rebelo) (rádio) [...] (ANTELO, 1984, p. 11-14).

Inclusive, muitos deles, antes de escreverem para Cultura Política, estiveram do lado oposto do regime implantado por Getúlio Vargas, mas no momento da publicação do periódico acabaram emprestando a sua pena com o intuito de registrar colaborações que pudessem firmar as mudanças sociais, políticas e culturais pelas quais passava o país após a chegada de Vargas ao poder. 


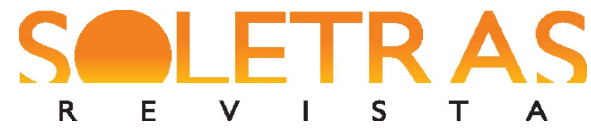

N. 40 - 2020.2 - PATRICIA APARECIDA GONÇALVES DE FARIA

No Brasil, um caso muito particular permeou a atividade de muitos artistas, como Candido Portinari, Graciliano Ramos, Carlos Drummond de Andrade e José Lins do Rego, entre outros, que estiveram ao mesmo tempo, dentro e fora da política governamental, pois apesar de estarem ligados ao governo pelas funções empregatícias que exerciam, não deixavam de manter os seus posicionamentos, ideologias e olhar crítico.

Grande parte destes intelectuais, literatos, arquitetos, músicos e pintores, entre outros, foram reunidos durante o ministério de Gustavo Capanema, durante os anos de 1934 e 1945, nomeados como a constelação de Capanema. Portanto, estes "funcionários do estado" viviam sob a ótica de um duplo viés, pois precisavam exercer seu trabalho junto ao Estado por motivos financeiros, todavia, sem deixar-se alienar perante às práticas políticas adotadas. Além destes intelectuais, existiam, ainda, outros grupos que preferiam adotar uma única perspectiva, ou seja, se rendiam aos encantos do governo e emprestavam o seu trabalho artístico em prol da propagação dos propósitos governamentais.

Antonio Candido, no prefácio da obra de Ségio Miceli, Intelectuais à brasileira, analisa essa relação peculiar entre os intelectuais e o estado durante o governo Vargas.

Mas o fato é que no processo estão envolvidos os homens, com a sua carne e a sua alma, de modo que conviria acentuar mais que um Carlos Drummond de Andrade "serviu" o Estado Novo como funcionário que já era antes dele, mas não alienou por isso a menor parcela da sua digniddae ou autonomia mental. Tanto assim que as suas idéias contrárias eram patentes e foi como membro do gabinete do ministro Capanema que publicou os versos políticos revolucionários de Sentimento do mundo e compôs os de Rosa do povo. Já um Cassiano Ricardo se enquadrou ideologicamente e apoiou pela palavra e pela ação, porque o regime correspondia à noção de democracia autoritária e nacionalisa (CANDIDO, 2001, p. 74).

Assim como Carlos Drummond de Andrade serviu o Estado, sem participar diretamente da máquina propagandística do Estado Novo, podemos afirmar que o escritor de Vidas secas também conseguiu manter o seu equilíbrio como escritor, funcionário do estado e colaborador de Cultura Política, não se rendendo em nenhum momento em suas obras à ideologia vigente, ao contrário, colaborou em um periódico dipiano sem precisar citar abertamente o nome de Getúlio Vargas, como muitos dos colaboradores da revista.

Nesse sentido, conclui-se que durante os quatros anos de existência, a revista conseguiu 


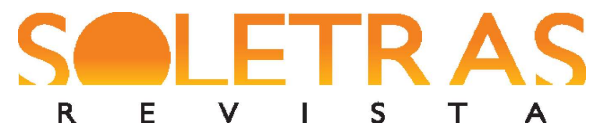

N. 40 - 2020.2 - PATRICIA APARECIDA GONÇALVES DE FARIA

atingir as suas principais finalidades que eram, sem dúvida, auxiliar na construção e consolidação do mito Vargas. Para tal fim contou com escritores empenhados em divulgar os estudos realizados em diversos setores da cultura e da política, de modo que muitos destes colaboradores, em seus escritos, criticaram a democracia da Primeira República com o intuito de fundamentar as propostas de construção de uma nova sociedade, que seria conduzida pelo regime instaurado em 1937, o Estado Novo.

\section{Os escritos de Graciliano Ramos}

A colaboração de Graciliano Ramos em Cultura Política se deu entre os anos de 1941 a 1944, representando a mais duradoura de suas contribuições em um único periódico. De sua autoria, foram publicadas 25 crônicas, sendo 21 nos anos de 1941 e 1942, duas em 1943 e duas em 1944. Deve-se esclarecer que as primeiras 18 foram estampadas nos 18 números iniciais da revista, na seção intitulada "Quadros e costumes do Nordeste"; quatro se encontram em "Quadros e costumes regionais"; duas estão em "Quadros regionais" e apenas uma na seção "Literatura".

As crônicas publicadas por Graciliano Ramos na seção "Quadros e costumes do Nordeste" não apresentavam títulos, mas apenas o número da crônica e o nome do seu autor. Portanto, em "Quadros e costumes do Nordeste" foram publicadas as seguintes crônicas: I (1941), II (1941), III (1941), IV (1941), V (1941), VI (1941), VII (1941), VIII (1941), IX (1941), X (1941), XI (1942), XII (1942), XIII (1942), XIV (1942), XV (1942), XVI (1942), XVII (1942), XVIII (1942).

Na seção "Quadros e costumes regionais" foram estampadas quatro crônicas, que receberam títulos, sendo: “A decadência de um senhor de engenho" (1942), "Recordações duma indústria morta" (1942), "Uma visita inconveniente" (1942) e "Está aberta a sessão do júri” (1943).

Na seção "Quadros regionais", Graciliano Ramos colaborou com duas crônicas, intituladas como "Um homem notável" (1943) e "A viúva Lacerda" (1944). E, por fim, na seção "Literatura”, publicou apenas a crônica "Booker Washington” (1944).

Anos mais tarde, 24 das 25 crônicas foram reunidas nas obras póstumas Viventes das Alagoas (1962) e Linhas tortas (1962), sendo que 22 se encontram em Viventes das Alagoas e 


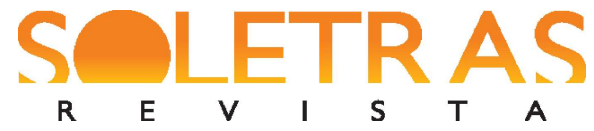

N. 40 - 2020.2 - PATRICIA APARECIDA GONÇALVES DE FARIA

apenas duas crônicas "A viúva Lacerda" e "Booker Washington" em Linhas Tortas, ambas edições publicadas pela editora Martins. A crônica "Uma visita inconveniente", por sua vez, permaneceu inédita, em livros até 2012, quando o estudioso Thiago Mio Salla a publicou em Garranchos: textos inéditos de Graciliano Ramos.

As publicações póstumas Linhas Tortas e Viventes das Alagoas foram editadas pela esposa Heloísa Ramos, pelo filho Ricardo Ramos e pelo seu genro James Amado. Portanto, as crônicas que pertenciam à seção "Quadros e Costumes do Nordeste" foram todas publicadas em Viventes das Alagoas e receberam os seguintes títulos:

- "Carnaval" - originalmente "Quadros e costumes do Nordeste I" (ano 1, n.1, mar. 1941);

- "D. Maria Amália" - originalmente "Quadros e costumes do Nordeste II" (ano 1, n.2, abr. 1941);

- "O moço da farmácia" - originalmente "Quadros e costumes do Nordeste III" (ano 1, n.3, maio 1941);

- "Casamento" - originalmente "Quadros e costumes do Nordeste IV" (ano 1, n. 4, jun. 1941);

- "Ciríaco" - originalmente "Quadros e costumes do Nordeste V" (ano 1, n. 5, jul. 1941);

- "Habitação" - originalmente "Quadros e costumes do Nordeste VI" (ano 1, n. 6, ago. 1941);

- "Teatro I" - originalmente "Quadros e costumes do Nordeste VII" ( ano 1, n. 7, set. 1941);

- "Teatro II" - originalemnte "Quadros e costumes do Nordeste VIII" ( ano 1, n. 8, out. 1941);

- "Bagunça" - originalmente "Quadros e costumes do Nordeste IX" ( ano 1, n. 9, nov. 1941);

- "D. Maria" - originalmente "Quadros e costumes do Nordeste X" (ano 1, n. 10, dez. 1941);

- "Libório" - originalmente "Quadros e costumes do Nordeste XI" (ano 2, n. 11, jan. 1942);

- "Desafio" - originalmente "Quadros e costumes do Nordeste XII" (ano 2, n. 12, fev. 


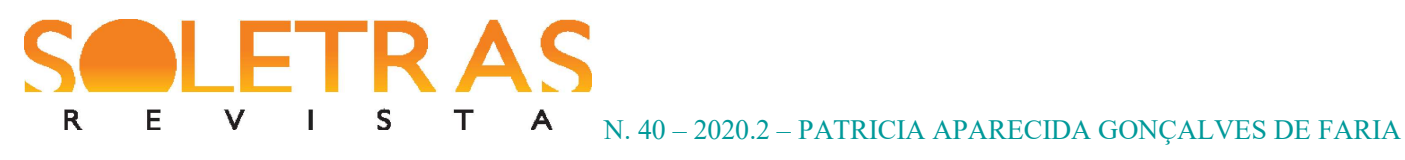

1942);

- "Funcionário Independente" - originalmente "Quadros e costumes do Nordeste XIII" (ano 2, n. 13, marc. 1942);

- "Um antepassado" - originalmente "Quadros e costumes do Nordeste XIV" (ano 2, n. 14, abr. 1942);

- "Um homem de Letras" - originalmente "Quadros e costumes do Nordeste XV" (ano 2, n. 15, maio. 1942);

- "Um gramático" - originalmente "Quadros e costumes do Nordeste XVI" (ano 2, n. 16, jun. 1942);

- "Dr. Pelado" - originalemnte "Quadros e costumes do Nordeste XVII" (ano 2, n. 17, jul. 1942);

- "Transação de Cigano" - originalmente "Quadros e costumes do Nordeste XVIII" (ano 2, n. 18, ago. 1942);

Como é possível observar, as 18 crônicas iniciais foram publicadas na seção "Quadros e Costumes do Nordeste" sem interrupção, ou seja, contemplando todos os números de Cultura Política. Com a extinção da seção, Graciliano passou a colaborar em "Quadros e Costumes regionais" publicando quatro crônicas, que a partir de então deixaram de ser enumeradas e passaram a receber títulos. Convém destacar que, desta seção, apenas três crônicas foram publicadas em Viventes das Alagoas e a outra só foi publicada em livro em 2012. Em Cultura Política elas aparecem desta forma:

- "Quadros e costumes regionais", intitulada "A decadência de um senhor de engenho" (ano 2, n. 19, set. 1942);

- "Quadros e costumes regionais", intitulada "Recordações duma indústria morta" (ano 2, n. 20, out. 1942);

- "Quadros e costumes regionais", intitulada "Uma visita inconveniente" (ano 2, n. 22, set. 1942);

- "Quadros e costumes regionais”, intitulada "Está aberta a sessão do júri” (ano 3, n. 25, mar. 1943);

Com o fim da seção “Quadros e Costumes Regionais”, Graciliano publicou apenas duas 


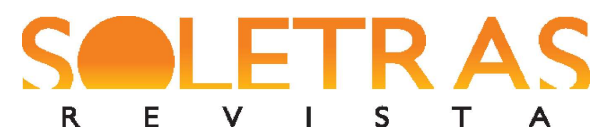

N. 40 - 2020.2 - PATRICIA APARECIDA GONÇALVES DE FARIA

crônicas na seção "Quadros regionais". Apenas uma destas crônicas foi publicada em Viventes das Alagoas.

- “Quadros regionais”, intitulada "Um homem notável” (ano 3, n. 27, maio. 1943);

A outra crônica publicada na seção “Quadros regionais” está presente na obra Linhas Tortas:

- "Quadros regionais” intitulada “ A viúva Lacerda” (ano 4, n. 42, jul. 1944);

E finalmente, na seção "Literatura", Graciliano colaborou com a sua última crônica em Cultura Política, que também está publicada em Linhas Tortas.

- "Literatura" intitulada "Booker Washington" (ano 4, n. 43, jul. 1944);

Ao comparar as crônicas que foram publicadas em Cultura Política com as presentes nas obras póstumas, podemos dizer, grosso modo, que a classificação e a organização possuem problemas tanto nas edições de Linhas Tortas quanto nas edições de Viventes das Alagoas. Dentre estes problemas, encontramos a ausência de informações bibliográficas essenciais, como o local e a data da primeira publicação das crônicas. A omissão destes dados, portanto, atrapalha em alguma medida o entendimento exato do percurso do cronista Graciliano Ramos, uma vez que a obra não leva em consideração a intervenção exercida no periódico e o período de sua publicação.

Linhas Tortas, que está em sua $21^{\text {a }}$ edição (2005), apresenta características documentais que abrangem a produção do escritor que vai de 1915 a 1952. Noutras palavras, o volume está organizado e dividido em seções que agrupam diferentes fases da escrita de Graciliano Ramos. A intenção do título é enfocar a "humildade" de alguns escritos que se encontram organizados na obra remetendo à ideia de fragilidade, imprecisão e inferioridade de determinados escritos do autor em diversos periódicos.

A primeira edição de Viventes das Alagoas reunia 36 crônicas e dois relatórios enviados por Graciliano Ramos, nos anos de 1929 e 1930, ao governador do estado de Alagoas, quando ainda era prefeito em Palmeira dos Índios. A partir da $15^{\mathrm{a}}$ edição, pela editora Record, 


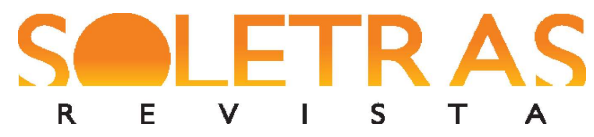

N. 40 - 2020.2 - PATRICIA APARECIDA GONÇALVES DE FARIA

acrescentaram mais duas crônicas inéditas em livros: "Antônio Silvino" e "Comandantes de Burros".

Em Viventes das Alagoas encontramos problemas graves de edição e organização, uma vez que as crônicas foram apresentadas sem serem agrupadas por eixos temáticos e nem tiveram, ao menos, citado o nome da seção ou do periódico em que foram publicadas pela primeira vez. Logo, não estão datadas e, consequentemente, não há uma ordem que situe o leitor em relação ao momento em que foram estampadas em Cultura Política ou outro periódico.

Na edição de número 18, organizada por Wander de Melo Miranda, houve uma tentativa de sanar os problemas, contudo, equívocos ainda permaneciam, conforme destaca Thiago Mio Salla em sua tese de doutorado O fio da navalha: Graciliano Ramos e a revista Cultura Política.

\begin{abstract}
A última edição do livro (19a edição lançada pela Record em 2007), que também fez parte do mesmo projeto de reedição das obras do autor, supervisionado por Wander de Mello Miranda, procurou solucionar tais lacunas, mas as deficiências continuaram. A começar pela própria "Nota do editor" em que se afirma: "Esta nova edição de Viventes das Alagoas teve como base a $1^{\text {a }}$ e a $15^{\text {a }}$ edição do livro, publicado pela J. Olympio". Como se sabe, a $1^{\text {a }}$ edição de tal volume foi lançada em 1962 pela Martins, sem a participação da José Olympio. Além disso, foram recuperadas informações bibliográficas da primeira publicação em periódico dos textos de Cultura Politica e de mais oito crônicas saídas em jornais cariocas e alagoanos, o que manteve o restante dos escritos sem a especificação dos locais e datas da veiculação inicial na imprensa (SALLA 2010, p. 37-8).
\end{abstract}

Outro equívoco encontrado em Viventes das Alagoas está relacionado à escolha do seu título. Noutras palavras, as crônicas em Cultura Política se encontravam basicamente na seção "Quadros e Costumes do Nordeste" de modo a retratar os costumes, o cotidiano, o folclore e a tradição do nordeste como um todo e não apenas de Alagoas, estado natal do escritor.

Ao analisar as publicações de Graciliano Ramos em Cultura Política: revista mensal de estudos brasileiros verifica-se que foram introduzidas notas do editor com o intuito de induzir e direcionar a leitura das crônicas.

Logo, na publicação de estreia de Cultura Política: revista mensal de estudos brasileiros, volume 1, número 1 de março de 1941, o editor do periódico já utilizou a nota a fím de tecer algumas palavras acerca de Graciliano Ramos e da missão assumiria ao escrever sobre o nordeste brasileiro e a sua cultura. Além da apresentação de Graciliano Ramos como cronista 


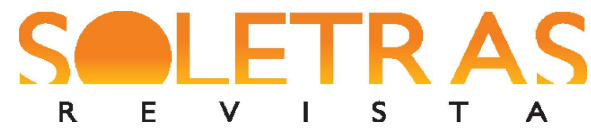

N. 40 - 2020.2 - PATRICIA APARECIDA GONÇALVES DE FARIA

responsável pela seção "Quadros e Costumes do Nordeste", ainda descreveu os aspetos que seriam abordados na crônica inaugural: o carnaval nas pequenas cidades do interior nordestino.

\begin{abstract}
Escritor e romancista consagrado entre os melhores do Brasil de hoje, tendo enriquecido a nossa literatura de ficção com obras fortes e cheias de personalidade, como São Bernardo, Angustia, Vidas Secas, Caetés, e com numerosos contos que se publicam incessantemente nos grandes jornais da capital da República e dos Estados - o autor desta crônica tomou o seu encargo fixar quadros e costumes da região do Brasil onde nasceu e viveu mais de trinta anos: o nordeste.

Neste número inaugural, ele nos dá um flagrante da grande festa popular - o Carnaval - tal como decorre nas cidadelas do interior nordestino. É um pequeno pedaço desse Brasil que ainda foge ao ímpeto renovador da civilização litorânea, desse Brasil tão diferente e tão grande. (ANDRADE, 1941, p. 236)
\end{abstract}

A revista utilizou notas do editor com o intuito de conduzir a leitura e a interpretação dos leitores. Portanto, na primeira parte da nota do editor, os elogios grandiosos a Graciliano Ramos não ocorreram por acaso, pois concomitantemente, almejavam valorizar os escritos do autor e mostrar a todos que a figura ilustre, que outrora não se adaptava aos moldes do Estado Novo, agora emoldurara as suas publicações numa seção fixa "Quadros e costumes do nordeste". Noutras palavras, a contratação de Graciliano como colaborador fixo de Cultura Política aumentava o prestígio do periódico e valorizava o discurso estatal, pois contava com um escritor talentoso e reconhecido que, apesar disso, anos antes fora preso por ter sido considerado com um oposicionista aos ideais implantados pelo governo Vargas, mas que naquele momento da publicação, estava disposto a colaborar com a revista Cultura Política.

$\mathrm{Na}$ segunda parte desta mesma nota introdutória, ainda tentando dirigir a leitura, a nota do editor enfatizou que os escritos de Graciliano iriam "fixar" e "flagrar" um "pequeno pedaço" do Brasil, um lugar distante que foi presenciado e vivido pelo autor por mais de trinta anos, ou seja, a nota do editor, mais uma vez, pretendeu "desficcionalizar" e aproximar da realidade os escritos de Graciliano Ramos.

Na tentativa de fugir da máquina propagandística do periódico, o autor de São Bernardo, adotou a estratégia de ficcionalizar, conforme aponta Raul Antelo em Literatura em revista, em que seus escritos oscilavam "às vezes entre o conto, a crônica de costumes e, mais raramente a crítica bibliográfica $[\ldots]$ ". 


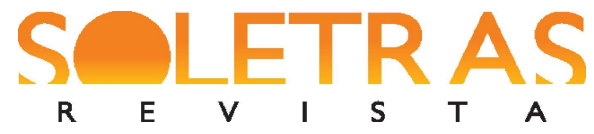

N. 40 - 2020.2 - PATRICIA APARECIDA GONÇALVES DE FARIA

Outra forma encontrada pelo autor para manter suas colaborações em Cultura Política foi colocar os fatos em um passado anterior à revolução de 1930, de modo a capturar da memória os acontecimentos cotidianos e desvelar questões inerentes às situações vivenciadas no cenário nordestino da época em que ainda vivia naquela região. No entanto, tais situações, vividas em um passado próximo, ainda se faziam presentes no cotidiano daqueles homens do sertão, logo, no momento da publicação de suas crônicas em Cultura Política, pouco havia se alterado naquele cenário inóspito.

Nesse sentido, tais acontecimentos e situações se perderiam, se não fossem recuperados por meio das narrativas do escritor, com estratégias e mecanismos próprios da linguagem literária, com os quais ele pretendia descortinar aquilo que se escondia por trás da fachada, contradizendo os ardis do editor, que almejava guiar a leitura por meio de suas notas e sublinhar as aspirações da revista.

Logo, em seus relatos, o autor tratou de temas presentes no dia a dia do homem nordestino de maneira ficcionalizada, primeiro porque não pertencia mais ao cenário nordestino enquanto escrevia suas crônicas e, segundo pelo fato de precisar se adequar aos moldes da revista getulista, inclusive equilibrando as palavras. Assim, ao ler as publicações em Cultura Política percebe-se que o cronista fez considerações sobre a forma de governar, de fazer transações econômicas, sobre os usos, os costumes e a linguagem da região nordestina, principalmente durante o período da Primeira República, sem, contudo, desvalorizar a região ou esquecer que situações semelhantes poderiam acontecer também no restante do Brasil.

O cronista, não praticou, em momento algum, a generalização destes fatos e muito menos citou o nome dos governadores, apenas mencionou de forma indireta os acontecimentos que induzem o leitor a pensar e a refletir sobre os procedimentos adotados em um período anterior e, até mesmo, contemporâneo à publicação da revista.

\section{Referências}

ANTELO, Raul. Literatura em revista. São Paulo: Ática, 1984.

ANDRADE, Almir de. Quadros e costumes do nordeste. Cultura Politica. Rio de Janeiro, ano1, n. 1, mar. 1941. 


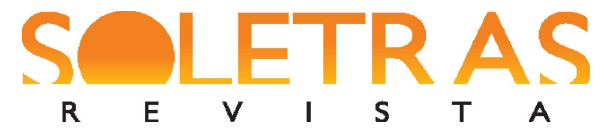

N. 40 - 2020.2 - PATRICIA APARECIDA GONÇALVES DE FARIA

CANDIDO, Antonio. Prefácio. In: MICELI, Sergio. Intelectuais à brasileira. São Paulo: Companhia das Letras, 2001.

PETERLE, Patricia. Ignazio Silone e Graciliano Ramos, um olhar dialógico. In: PETERLE, Patricia (Org). Ignazio Silone: ontem e hoje. Rio de Janeiro: Editora Comunità, 2010.

RAMOS, Graciliano. Linhas tortas. São Paulo: Martins, 1962.

. Viventes das Alagoas (Quadros e costumes do Nordeste). São Paulo:

Martins, 1962.

SALLA, Thiago Mio. O fio da navalha: Graciliano Ramos e a Revista Cultura Política. 2010. 721 f. Tese (Doutorado em Comunicação). Universidade de São Paulo, USP, 2010. Disponível em: http://www.teses.usp.br/index.php?option=com_content\&view=article\&id=64 \&Itemid= 194\&lang=pt-br. Acesso em 20 fev.2020.

VELLOSO, Mônica Pimenta. Cultura e Poder Político: uma configuração do campo intelectual In: OLIVEIRA, Lúcia Lippi; VELLOSO, Mônica Pimenta; GOMES, Ângela Maria de Castro (Org.). Estado Novo: ideologia e poder. Rio Janeiro: Zahar, 1982.

\title{
The written of Graciliano Ramos in the pages of Political Culture: monthly magazine of Brazilian studies
}

\begin{abstract}
Joining the practice of writing novels and short stories the to the press of the time, Graciliano Ramos (1892-1953) collaborated from the years of 1941 to 1944 in Cultura Politica: revista mensal de estudos brasileiros - monthly magazine of Brazilian studies - (1941-1944), the main publication of the Press and Advertising Department (PAD), controlled by the Estado Novo, which was responsible to send him to prision in 1936, without, at least, a formal accusation. Thus, considering the intellectual and literary path of the writer of Vidas Secas, this research aims, from theorists as Antelo (1984), Andrade (1941), Candido (2001), Salla(2010), Velloso (1982), among others, from at studying the characteristics of the magazine and its strategies to maintain the group of important people, such as Graciliano Ramos and, certainly, at lifting the author's publications of the magazine to verify the strategies of the writing used by the writer to help the State without, however, to surrender to the government ideology.
\end{abstract}

Keywords: Graciliano Ramos. Cultura Política. Chronicles.

Recebido em: 20 de abril de 2020 .

Aceito em: 18 de junho de 2020. 